\title{
CONCEPTUALISING HUMAN NEEDS AND WELLBEING
}

\author{
Des Gasper \\ Institute of Social Studies, The Hague
}

\begin{abstract}
Pre-final draft of a 2007 chapter that appeared in :
Wellbeing in Developing Countries: New Approaches and Research Strategies, edited by I. Gough and J.A. MacGregor, Cambridge University Press, pp. 47-70.
\end{abstract}

\section{NEEDS AND WELLBEING: ISSUES AND THEMES}

What are the relationships between human needs and human wellbeing? I will address the question by considering the conceptual linkages between these two umbrella categories. This requires investigation of the nature of each of them as a family of concepts. That is attempted in Sections 3 and 4 of the paper. I briefly point to the further topic of their empirical connections in Section 5. Bracketing these discussions, the opening and closing parts of the paper consider and compare human needs and human wellbeing as research programmes. How far is the wellbeing programme a continuation or successor to the tradition of thinking and investigation on human needs, and what lessons may arise from the somewhat troubled history of research on needs?

The rise of wellbeing as an important, if not yet major, research focus in development studies and policy and more widely is extremely welcome and long overdue. As recently as 1994, Routledge's The Social Science Encyclopedia (Kuper \& Kuper 1994) could appear without an entry on wellbeing or quality of life or happiness. Even in two excellent late 1980s textbooks on the emergent field of economic psychology (Furnham \& Lewis 1986; Lea, Tarpy \& Webley 1987) wellbeing remained a minor theme. Lea et al. in over 500 pages did not discuss it as a separate topic; Furnham and Lewis devoted just four pages to the relationship between wealth and happiness. Often wellbeing was considered no topic for science; or income and wealth remained largely taken for granted as the synthetic concerns which would reflect or provide opportunity for every other value. 
Quality of life research has, it is true, been active since the 1960s, but it has been a delimited specialist interest, largely confined to and within rich countries. The attention in the 1970s to the Physical Quality of Life Index (PQLI) did not have much impact or endure. Only during the 1990s with the Human Development school centred in the United Nations Development Programme (UNDP) can we say that a broader quality-oflife focus became common in studies of low-income countries. Importantly, UNDP's work has treated both income-poor and income-rich countries in the same frame.

Subjective wellbeing (SWB) research too has been a partly separate, specialist interest of some psychologists, largely limited, again, to and within rich countries. Only with the large scale entry of participatory methods of investigation into development studies in the 1990s has attention to SWB become substantial worldwide, sometimes even challenging the dominance of income measures.

While applauding the rise of wellbeing research, and its present appearance in development studies, we should remember that this is overall still rather little, rather late. We should diagnose old and new resistances that this research stream may face, and its internal limitations and problem-areas, in order to avoid or at least mitigate a subsequent phase of decline and even rejection such as occurred for work on basic human needs. The substantial 1970s wave of work on needs, the PQLI etc., was strongly criticised, opposed and to a large extent set aside in the 1980s and early 1990s. The opposition came from multiple sources, including, for example, radical Greens like Ivan Illich, not only from true believers in markets and economic growth. What warnings and lessons for tactics and strategy can we draw from the rise and fall of basic human needs research and policy in the 1960 s to 1980 s?

The starting point for this paper is the hypothesis that conceptual clarification in these areas, wherever possible, is essential and not a luxury pastime. The needs movement foundered for long in a mire of messy conceptualisation. The work on wellbeing has a basic armoury of concepts from psychology, ethics and welfare economics (seen in the work of, for example, Ed Diener, Derek Parfit and Amartya Sen), but may require more standardisation of a shared, integrative and tested set of terms. While no set of terms can be more than an imperfect set of working simplifications, not all sets are equally adequate. Better terminology can smooth communication between and within scientific 
communities, and influence and educate communication in wider arenas. Simplified concepts are an inevitable requirement in domains of social policy where research must interface with politics, politicians, planning, planners, public debate and debating publics. The difficulty is that each area of research and each forum of public debate tends to establish its own set of working simplifications to match its context-specific concerns. Even if internally adequate, the set may fail to match the sets of terms created in other contexts. Continuing with inconsistent and often unconsidered usages has a price. Careful attention is required then to which simplified schema or linked set of schemas will be relevant and workable, rather than risk that the wellbeing programme sinks into the mire or becomes pushed into a denigration zone as 'old politics', 'old thinking', like needs approaches were. Is such a conceptual framework attainable?

The paper's main focus is on concepts, as a basis for refining models of wellbeing and needs and their relations. We will address the following misconceptualisations:

- First, that 'needs' is a single category; instead we must distinguish at least descriptive, instrumental and normative modes, and several different levels within each;

- Second, that 'Wellbeing' (WB) is a single unified category or just SWB (itself presumed to be unitary), or just either 'Objective Wellbeing' (OWB) or SWB; instead we must distinguish again between several levels and related categories.

More refined conceptualisation serves to establish needs approaches and wellbeing research as methodologies or frameworks in investigation, sets of questions rather than just packages of answers -- in other words, as research programmes.

The WeD project, with its multidisciplinary base and use of Doyal and Gough's complex theory of need, has a good start in conceptualisation. This paper looks for complementary insights. It does not attempt to cover all the important aspects of needs discourse and focuses instead on the possible interrelations with wellbeing discourse. 


\section{THE FALL AND RISE OF NEEDS THEORY}

In 1989, The Economic Journal, journal of the UK Royal Economic Society, published a ninety page commissioned survey of development economics by Nick Stern, later the Chief Economist and Senior Vice President of the World Bank (2000-2003) and subsequently head of the Government Economic Service in the UK Treasury. The World Bank of the 1970s had espoused and to some degree pursued a policy priority to basic needs, largely interpreted as basic material needs that were to be conceptualised and specified by government planners, often economists. The approach was familiar from much earlier planning, for example in wartime, in state socialist countries and the Government of India and in provision for refugees. Stern, the commissioned voice of late 1980s establishment development economics, expressed that mainstream's rejection and expulsion of what was now an alien conceptual body:

'...the basic needs ideas [of 'the so-called "basic needs" approach'; 1989: 644] have real problems. What needs are basic and more worryingly what levels are held to be essential minima? What if these levels are infeasible...? Who decides which needs are basic and the appropriate level? In what sense are they basic if people who can afford to attain them do not choose to do so? ... [The questions] are not easy to answer in a satisfactory way and one is left with a certain scepticism about the approach' (Stern 1989: 645).

Ironically, during his later tenure as World Bank Chief Economist (2000-2003) and then as a Permanent Secretary in the UK Treasury, Stern inherited and formally endorsed the late 1990s commitments to the Millennium Development Goals, a programme of priority to basic needs fulfilment (even if only slow and partial) that represented proposed answers to his late 1980s questions. Some needs, such as for life of a reasonable duration, freedom from easily controlled diseases, literacy and numeracy, freedom from physical violence, are specifiable in ways that can satisfy the demands of 'a certain scepticism'; as was apparent in 1989 to those who were ready to see. However, setting criteria of perfection for other approaches serves to eliminate them from consideration before one then proceeds with one's own thoroughly imperfect approach. 
How did the basic needs approach fall from favour? In addition to political economy and political circumstance, the following weaknesses contributed: first, lack of clarity in the approach on its diverse sources and their distinct and sometimes competing characters; second, lack of a technical language that was both sufficiently refined and systematised yet sufficiently vivid, memorable and thus usable; and third, lack of a political language that was sufficiently flexible and appealing.

How did the basic needs approach revive and evolve into more robust forms or successors after the attacks and denigration in the late 1970s and 1980s? First, I suggest, by better distinguishing between diverse modes of needs theorising; second, by much stronger conceptualisation; and third, by engaging more savvily in the politics of ideas.

In distinguishing modes, normative needs theorising and instrumental needs theorising were explicitly distanced from fixed commitments in psychological theory, as we will see in section 3. In conceptualisation, relevant distinctions were introduced or standardised:

- between needs (as priority functionings) and satisfiers (things which could allow those functionings); satisfiers vary enormously whereas the needs they serve can be shared and stable; we can thus distinguish levels of generality and distinguish stages in causal sequences;

- between attaining/attainment and being able to attain (or in other words between functioning and capability); and between guaranteeing attainments and strengthening capabilities;

- between orders of priority; for example, education and health and security are often given highest priority, above even employment and housing; and

- between various types of policy-relevant activity: setting a policy framework for discussing ends, versus prioritising, versus setting targets, versus attempted public sector delivery.

The systematising work along these lines by Johan Galtung, Carlos Mallmann and others in the late 1970s (see e.g. Lederer 1980) was too late and incomplete to save the basic needs approach from the antagonistic forces that arrived in power. The 
subsequent period out of favour was used by some determined and creative theorists of needs (or, in Sen's case, of a next generation of concepts), such as Penz, Braybrooke, Max-Neef and Sen, to systematise various conceptual and theoretical insights. Len Doyal and lan Gough took over this improved toolbox, and integrated a wealth of relevant work from the diverse sciences of wellbeing.

Peter Penz, in a 1986 book that influenced Doyal and Gough, had patiently deconstructed the mainstream economics principle of consumer sovereignty, which holds that our criterion of assessment should simply be what consumers choose or would choose. The principle proves to be massively under-defined, since preferences are in part endogenous and for several other reasons. It is only defensibly operationalisable by large-scale supplementation by normative principles of a quite different character that grow out of thinking about the substance of human interests. Penz was led back first to happiness as a criterion, abandoned long earlier by economists but much more measurable nowadays; but that criterion too is weakened by its endogeneity and by many of the same problems as face preference-fulfilment. He concluded instead in favour of basic needs, understood as the requirements of physical and mental health and other basic human interests (a modicum of security and social inclusion, etc.); as giving a conception that could rationally command the support of diverse political viewpoints, by ensuring the conditions needed for each of their diverse principles to acquire relevance (Penz 1991).

Thus besides better conceptualisation, needs approaches became more effectively located in wider intellectual and political space. More appealing and more ethically charged labels were found - 'human development' and 'human security' (e.g. St. Clair 2004, 2005; Gasper 2005a) - and then connected to the powerfully focusing and motivating theme of human rights. Attention-catching, thought-provoking indices were devised: the Human Development Index (HDI) and its siblings. And an insulated, influential organisational niche was created in 1989: the UN's Human Development Report Office was created with intellectual independence yet public access and influence. In all three respects - labels, indices and niche - Mahbub ul Haq's contribution was vital. 
The next two sections concentrate on the clarification of modes and the systematisation of concepts, first for needs and then for wellbeing and the connections. We return in the final section to the politics of ideas and consider possible implications for the strategy of the present-day research programme on wellbeing.

\section{CONCEPTUALISING HUMAN NEEDS}

Despite considerable criticism, including in forms more hostile than Stern's (e.g. Springborg 1981), the term 'need' continued and continues in massive, daily use in many fields of social policy (see Witkin \& Altschuld 1995, Brazelton \& Greenspan 2000), management, and marketing (see Jackson, Jager \& Stagl 2004), including in the international social policy areas of the Millennium Development Goals and humanitarian aid. Needs language caters to extremely widespread functional requirements - to make analyses of motivation thicker and more realistic, and to indicate instrumental roles, typically towards priority objectives; but it is hard to order, precisely because of how widespread and varied such roles are.

\section{Meanings and obscurities}

A recent study of needs assessment in humanitarian emergencies reported that the term 'need' has become a source of confusion there, given, it proposed, at least three substantially different meanings in the humanitarian context.

1. Basic human needs ('food is a basic human need')

2. A lack of basic human needs ('these people need food')

3. A need for relief assistance or some other humanitarian intervention ('these people need food aid') (Darcy \& Hofmann 2003: 16).

The first meaning is need as a noun, something that is needed; the second is need as a verb, about the needing of the noun. Darcy and Hofmann warn that a noun-language of need is sometimes misleading. '.. discussion of the need for protection tends to "commodify" a concept that cannot be reduced to these terms' (ibid: 17). The more important distinction is between the first two meanings and the third, which refers to a particular method or satisfier (e.g. food aid) for fulfilling the more general need (food). '...needs assessment is often conflated with the formulation of responses, in ways that 
can lead to resource-led intervention and close down other (perhaps more appropriate) forms of intervention' (ibid. 2003: 16), for example monetary aid or employment provision rather than relief food supply. ii

Darcy and Hofmann propose to drop and replace the term 'need' and replace it by other terms, including 'risk', particularly 'acute risk'. In addition to the ubiquity and endlessness of chains of implied requirements (or, to use a less ambiguous term, requisites), and the noun-verb ambiguity, they hold that use of the term 'risk' is less likely to lead to the conflation of problem assessment and response formulation. In contrast to the word 'need', the word 'risk' will not be applied to response formulation too. Yet, after these remarks, and like the rest of us, Darcy and Hofmann's report continues using the concepts of need and needs intensively.

So although needs language can be a source of confusion at present in humanitarian assistance, the appropriate route may be to upgrade rather than avoid it. We can go far further in clarification than do Darcy and Hofmann. It is sobering to consider that longstanding clarifications remain little known.

\section{Modes of Needs Discourse}

Philosophers like Brian Barry (1965, 1990), Paul Taylor (1959) and David Wiggins (1985) consolidated a number of important insights about needs language. Several of them are captured in a 'relational formula': $A$ needs $S$, if $S$ is a necessary condition for $A$ to achieve $\mathrm{N}$, and $\mathrm{N}$ is either directly an approved priority or is a necessary condition for achievement of the accepted approved priority P. Policy-oriented scholars took further steps, adding knowledge drawn from the complexities of practical use and policy debate. David Braybrooke's Meeting Needs (1987) and Doyal and Gough's A Theory of Human Need (1991), in particular, highlighted that the chains of instrumental linkage can be long. Since they definitely do not have to contain only two or three links, a more complex vocabulary or usage is required. They also insist that the discourse of instrumental linkages towards priority objectives must be distinguished from the discourse of specieswide behavioural potentials and propensities. This distinction had been obscured by optimistic evolutionary ideology, from both the political left and right.

Doyal and Gough's chapter 'The Grammar of "Need”' distinguished thus between: 
1. 'a drive or some inner state that initiates a drive.... Here "need" refers to a motivational force instigated by a state of disequilibrium or tension set up in an organism because of a particular lack (Thompson [sic], 1987, p.13)' (Doyal \& Gough 1991: 35);

and

2. 'a particular category of goals which are believed to be universalisable' (1991: 39), because they are necessary conditions for avoidance of serious harm.

This distinction is not consistently respected even in social science usage. I became more aware of this during a 1993-95 UK ESRC research project on human needs and wants, part of a multi-project programme on social science analyses and interpretations of global climate change sponsored by the Battelle Foundation. The programme led to a four-volume study, edited by Steve Rayner and Elizabeth Malone (1998), which included an extensive chapter on needs and wants (Douglas, Gasper, Ney \& Thompson 1998). During a workshop in the needs-wants project it became evident that the participants psychologists, economists, philosophers, sociologists, anthropologists - held to no consistent usage of 'need', as individuals, not only across disciplines. Yet most of us had read and thought about needs since the 1960s or 1970s. We jumped between different usages almost from one sentence to the next: between the variants identified by Darcy and Hofmann - more basic needs versus satisfiers; and verbs versus nouns - and also between needs as explanatory forces and factors, needs as (pre)requisites, and needs as particular sorts of moral priority claims.

Investigation in a range of literature confirmed that pervasively inconsistent usage existed not simply between different disciplines but was ingrained in the usages within disciplines. Sometimes need was referred to as an inbuilt (whether inborn or inculcated) drive, sometimes as the implied requirement of a given objective, sometimes as a normative priority, sometimes as presumptively all three at once - rarely with any explication or apparent awareness of this complex and fluctuating usage. By distinguishing modes, we can identify when jumps occur, consciously examine proposed linkages and jumps, and assess when they are acceptable and when not. 
The prevalence of not only multiple usages but unannounced and even undetected midparagraph jumps between meanings suggested that a more emphatic and elaborate statement of grammar was required than in Braybrooke or Doyal and Gough. I proposed a fuller grammar for the field in the chapter which emerged for the Battelle study (Douglas et al. 1998) and more thoroughly in a 1996 paper. The main ideas appear in an updated version in Gasper (2004a: Ch.6). Here I will outline part of that framework, and then in Section 4 relate it to ideas concerning wellbeing.

We can usefully distinguish three modes. In mode A, 'need' is a term used in evaluatively neutral description or explanation: to refer to a want or a drive or a potential. In mode B, a 'need' is a requisite for achieving an objective. Thus the requisite's normative necessity depends on the status of the objective, and on how essential it is for reaching that objective. In mode $\mathrm{C}$, a 'need' establishes a strong normative claim since the objective is a normative priority, and the requisite is indeed essential. In all modes there is an ambiguity inasmuch as 'need' is sometimes applied to the objective and sometimes to the implied requisite. Further, whereas in mode A 'need' typically figures as a noun, a presence, in mode $B$ it can often appear as a verb, a lack.ii

What are the relationships of the modes? First, mode $\mathrm{C}$, concerning priority objectives and requisites, is of course a subset of mode $B$ which concerns any objectives and requisites. But we might sometimes encounter references to an instrumental mode as containing only the instrumental usages which are not in mode $C$. Second, mode A often overlaps with the other two, when fulfilment of some mode A need, some want or drive or potential, is seen as necessary for achievement of a specified objective (mode B), which may be a normative priority (mode C). Table 2.1 illustrates these interrelations, showing five possible cases. The five cases are:- purely in mode $A$ (case 1); purely in mode $B$ (cases 4 and 5); in both modes (cases 2 and 3 ). If in mode $B$, a need can be either also in mode $\mathrm{C}$ or only of mode B. We examine these cases further in Section 4. 
Table 2.1. A modal analysis of the five types of 'need'

\begin{tabular}{|c|c|c|c|}
\hline & \multirow{2}{*}{ NOT MODE B } & \multicolumn{2}{|c|}{ MODE B } \\
\cline { 3 - 4 } & & MODE B & MODE C \\
ONLY & ALSO \\
\hline MODE A & Type 1 & Type 2 & Type 3 \\
\hline NOT MODE A & - & Type 5 & Type 4 \\
\hline
\end{tabular}

The threefold division of modes is an extension and generalisation of Doyal and Gough's contrast between a motivational force and an universalisable value or goal. Mode A covers more types of descriptive entity than only types of motivational force and covers more motivational forces than only drives; mode $\mathrm{C}$ could cover more types of normative claimant than universalisable goals; and we have, in addition, highlighted mode $\mathrm{B}$.

Distinguishing mode B too is important: it is widespread in social science and everyday usage; it is correspondingly highlighted in Taylor's (1959) classic semantic dissection; and, vitally, recognising it helps us to understand why and how the common conceptual slippage between modes $A$ and $C$ occurs.

If we check our framework against some dictionary definitions of need we find all modes in use, but no discipline appears to refer regularly to all three (see Table 2.2). One - the social science discipline with the greatest resources and political influence, economics has often tried to abandon the term altogether. Fortunately it remains the exception.

Table 2.2. A comparison of the modes employed in definitions of need

\begin{tabular}{|c|c|c|c|c|c|c|}
\hline & $\begin{array}{c}\text { ECONOMICS } \\
\text { DICTIONARY }\end{array}$ & $\begin{array}{c}\text { SOCIOLOGY } \\
\text { DICTIONARY }\end{array}$ & $\begin{array}{c}\text { PSYCHO- } \\
\text { LOGY } \\
\text { DICTIONARY }\end{array}$ & $\begin{array}{c}\text { POLITICS } \\
\text { DICTIONARY }\end{array}$ & $\begin{array}{c}\text { PHILOSOPHY } \\
\text { COMPANION }\end{array}$ & $\begin{array}{c}\text { DOYAL \& } \\
\text { GOUGH }\end{array}$ \\
\hline MODE A & - & $\mathrm{X}$ & $\mathrm{X}$ & & & $\mathrm{X}$ \\
\hline MODE B & - & $\mathrm{X}$ & & $\mathrm{X}$ & $\mathrm{X}$ & \\
\hline MODE C & - & - & $(\mathrm{X})$ & $(\mathrm{X})$ & $(\mathrm{X})$ & $\mathrm{X}$ \\
\hline
\end{tabular}

The Penguin Dictionary of Economics ( $5^{\text {th }}$ edition) ignores the term 'need' (and 'basic need'). This is not an outlier case. Mainstream economics has systematically shunned needs-theorising, partly due to a confusion between modes. (Vivid examples of both shunning and confusion, over several decades, are collected in Jackson et al. 2004.) 
Resistance to engaging in mode $\mathrm{C}$ discourse on ethically/publicly reasoned priorities as opposed to reliance on individual preferences alone, and objection further to claims that the State should then provide such priority items, has contributed irrationally to rejection of mode A and mode B discourses too, as if the three were inseparable. Much of economics remains primitive or completely deficient in explanation of wants, as if this would impugn the sovereign consumer, and in investigation of human requisites, which can become politically embarrassing for the privileged. For study of human requisites Dasgupta (1993) is a noble exception; he endorses the N-word.

The Penguin Dictionary of Sociology (1994) records two meanings: first, a need as a factor that motivates individuals - this fits our mode $A$; and second, need as a functional prerequisite - this fits mode $B$.

The Penguin Dictionary of Psychology (2001) records what it considers are two main meanings and some subsidiary (more problematic or less common) ones. 1) 'Some thing or state of affairs which, if present would improve the wellbeing of an organism.' This seems to fit mode $\mathrm{C}$, if we take wellbeing as a normative category, as is implied by the name. However, the lack of specification of which type of organism (a bacterium?) leaves the ethical status of the needs in doubt. 2) 'The internal state of an organism that is in need of such a thing or state of affairs' - this concerns a lack, as compared to the first meaning, which concerned what would remedy a lack. In addition: 3a) a need as a drive - a mode A meaning, which the dictionary correctly warns often does not apply for mode $C$ needs; and $3 b$ ) a need as a motive or incentive, wish, desire or craving - in other words, other mode A meanings.

The Oxford Dictionary of Politics (2003) adopts mode B: 'what is required in order to do something or achieve some state of being.' It continues: 'Human needs', for example, have been taken to describe requirements which must be satisfied if harm to an agent is to be avoided'. If we deem 'harm' a morally charged term, then the supportive definition perhaps moves into mode C; likewise when, later in the entry, purported needs are the proposed 'requirements of human flourishing'. However, the language here is evaluative, indicating what is desirable, rather than prescriptive, indicating what is proposed for action in the light of all relevant factors. 
The Oxford Companion to Philosophy (1995) sits in the same way near the border of modes $B$ and $C$ but perhaps within mode $B$ : 'what an organism requires to live the normal life of its kind', with 'normal' promptly clarified as 'flourishing rather than merely surviving'. Absence of the need (or, to be precise, a need-satisfier) causes harm. But the definition speaks of any organism, not specifically human beings, which weakens any presumption that the flourishing involved (of say a mosquito) carries normative significance in a moral universe of humans.

Doyal and Gough's theory of need highlights the distinction between modes A and C (1991: Ch.3). It investigates the content of needs that derive from the requirements of being a competent member of one's society and of avoiding fundamental harm. It does not highlight and define mode $\mathrm{B}$ in addition to modes $\mathrm{A}$ and $\mathrm{C}$.

Definition of only modes $\mathrm{A}$ and $\mathrm{C}$ leaves the two apparently quite different and evokes too little modal caution. The incoherent pattern of usage across disciplines can be better understood and remedied by delineation of mode $B$ in addition. We can then see how mode $B$ usage and mode $A$ usage are too easily slid into each other, since both are positive: normatively neutral. And we can see also, how mode $B$ and mode $C$ usages are too easily fused, since both use an instrumental logic and there is ambiguity often over whose are the objectives referred to (e.g. 'the organisation's objectives', 'the policy's objectives', 'society's objectives'). Overall, usage across the whole field, from mode A through to $\mathrm{C}$, can slide thus into an often incoherent, undifferentiated mire.

\section{Elements of normative needs discourse}

Within mode $\mathrm{C}$ discourse a number of further elements must be distinguished. One could similarly elaborate within mode A, as psychologists and phenomenologists do; but here we focus on normative needs discourse, as prelude to a discussion of well-being. Braybrooke identified the following constituent elements in normative needs discourse:

1. implicitly, a decision-making group deciding for a particular target population within a particular political community (the three can be identical but are often not);

2. a criterion/ target objective which one uses to determine need - for example, health or autonomy or a conception of human flourishing; 
3. a set of types of need, derived as proposed necessary implications of that criterion;

4. a set of levels, such as illustrated later in the middle column of Table 2.4, at each of which levels we specify satisfiers contributing towards the chosen criterion;

5. at each level, for each of the types of need, (where relevant) a specified indicator and a specified provision target.

For our present purposes a few points merit highlighting. First, concerning the instrumental linkages between levels: a satisfier can contribute to fulfilling several needs; a need/lack can often be met by many alternative satisfiers; and not all proposed satisfiers are effective. Second, within mode C (normative) needs discourse, each possible criterion of priority generates a particular specification of implied requirements, normatively fundamental needs. The criteria found in use range from as little as survival (to a normal human life-span) to as much as 'human flourishing' (Gasper 1996, 2004a). Thus, third, from an understanding of mode $C$ needs as the requisites for wellbeing, we see that different conceptions of wellbeing lead to different specifications of need. And fourth, each particular level chosen as the focus in needs discourse matches a particular sort of conception of wellbeing, as Section 4 will now show.

\section{CONCEPTS OF WELLBEING AND THEIR INTERRELATIONS WITH CONCEPTS OF NEED}

Conceptual confusion is widespread within the field of wellbeing too. One factor has been that mainstream economics, shielded and satisfied by its doctrine of people's wants/ preferences as the central and sometimes even only acceptable normative criterion, long avoided the empirical and conceptual investigation of wellbeing, abandoning it to other disciplines.

We should again distinguish several variants and several levels. The various concepts of wellbeing in use will be seen to correspond primarily to different levels. A contrast between modes is less important here, for wellbeing is more consistently a normative concept than is need. Perhaps ironically, this normative concept of wellbeing includes a major branch known as 'objective wellbeing', in contrast to so-called 'subjective wellbeing'. OWB centrally considers externally assessed and approved, and thereby 
normatively endorsed, non-feeling features of a person's life, for example matters like mobility and morbidity. SWB centrally refers to feelings and/or judgements of the person whose wellbeing is estimated.

If the approver is the person herself, and if feeling good is an approved feature, indeed, even the overriding approved feature, then we would have a case where the OWB and SWB categories overlap. In general, however, the approved features concern nonfeelings aspects: such as health, longevity, autonomy and access to desired or approved opportunities. Insofar as health covers mental health, then the categories can overlap there, for example with reference to depression or its absence. Further, the more that feelings are based on systematic and deep reflection, the more might SWB overlap in character with OWB.

The 'subjective' and 'objective' labels are often unsatisfactory. As Veenhoven, among others, stresses, the ambiguity in the meanings of OWB and SWB causes confusion and is pernicious yet soluble. The figure indicates that we need at least four categories not two. Feelings can be 'objectively' studied, by externals, as in case II in Table 2.3 below; and as in case IV in the figure, self-reports on feelings are sometimes valid and reliable measures. iv

Table 2.3. The scope for confusion in usage of 'subjective / objective wellbeing'

\begin{tabular}{|c|c|c|c|}
\hline & \multicolumn{2}{|c|}{$\begin{array}{c}\text { THE FOCUS OF MEASUREMENT / } \\
\text { ESTIMATION (main criterion) }\end{array}$} \\
\hline & & $\begin{array}{c}\text { 'Objective', as } \\
\text { focused on externally } \\
\text { approved non-feelings }\end{array}$ & $\begin{array}{l}\text { 'Subjective', as } \\
\text { focused on feelings }\end{array}$ \\
\hline \multirow[t]{2}{*}{$\begin{array}{c}\text { METHOD OF } \\
\text { MEASUREMENT / } \\
\text { ESTIMATION } \\
\text { (subsidiary criterion) }\end{array}$} & $\begin{array}{c}\text { 'Objective', as } \\
\text { external measurement } \\
\text { / estimation }\end{array}$ & $\begin{array}{c}\text { Case I: Focus on } \\
\text { externally approved } \\
\text { and estimated non- } \\
\text { feelings; } \\
\text { clearly 'OWB' }\end{array}$ & Case II \\
\hline & $\begin{array}{l}\text { 'Subjective', as using } \\
\text { subject's self-report }\end{array}$ & Case III & $\begin{array}{c}\text { Case IV: } \\
\text { clearly 'SWB' }\end{array}$ \\
\hline
\end{tabular}


The philosopher Derek Parfit (1984)'s influential list went one step further than an SWB/OWB division and contained three types of notion of wellbeing:

- Hedonism: wellbeing as pleasure;

- Desire theories: wellbeing as the fulfilment of preferences/desires;

- Objective list theories: wellbeing as the attainment of the elements in a list of what makes a life well-lived.

Hedonism represents a crude version of the SWB conceptualisation, crude because psychologists identify other aspects of feelings besides pleasure. Objective list theories correspond to OWB. Influenced by the practice of economics, Parfit adds preference fulfilment to the list. It is a distinct conception because preference fulfilment does not necessarily give pleasure and is not always in normatively approved forms. When we ask what the preferences are for or about, we get a hint that we may have to go further than a list of three. Are the preferences for commodities, for characteristics, for satisfaction, for (in Sen's terms) other-oriented agency objectives, or something else?

\section{Seven concepts of wellbeing}

If we take the categories added to micro- and welfare economics by Kelvin Lancaster, Sen and others, and connect them to traditional categories in economics and ethics, we obtain an extended narrative sequence of how control over resources connects through to human fulfilment, as outlined in Table 2.4 (to be read from bottom to top). 
Table 2.4. Relating concepts of wellbeing to the stages in Sen's enriched narrative of consumer choice, consumption and functioning

\begin{tabular}{|c|c|c|}
\hline $\begin{array}{l}\text { CONCEPTS OF } \\
\text { WELLBEING } \\
\text { (based on Gasper 2005b) }\end{array}$ & $\begin{array}{l}\text { ALTERNATIVE LEVELS OF } \\
\text { FOCUS IN STUDIES OF } \\
\text { WELLBEING: PUTATIVE } \\
\text { NARRATIVE SEQUENCE } \\
\text { (from bottom to top) } \\
\text { (source: Gasper 2004b) }\end{array}$ & $\begin{array}{l}\text { DOYAL \& GOUGH'S } \\
\text { LEVELS IN 'A THEORY OF } \\
\text { NEED' (1991) (with some } \\
\text { contents of the more limited } \\
\text { variant on their p.170, and } \\
\text { broad equivalences to levels } \\
\text { in the narrative sequence) }\end{array}$ \\
\hline 4D: Objective list IV & $\begin{array}{l}\text { HUMAN FULFILMENT } \\
\text { as value fulfilment }\end{array}$ & \\
\hline $\begin{array}{l}\text { 7: Pleasure/satisfaction = } \\
\text { SWB } \\
\text { (if we presume a crude } \\
\text { mental model) }\end{array}$ & $\begin{array}{l}\text { ‘Utility’ - as HAPPINESS } \\
\text { \&/OR SATISFACTION } \\
\text { (this is, clearly, not a unitary } \\
\text { category; different aspects } \\
\text { can be distinguished) }\end{array}$ & \\
\hline 6B. Preference fulfilment II & $\begin{array}{l}\text { ‘Utility' - as DESIRE } \\
\text { FULFILMENT }\end{array}$ & \\
\hline $\begin{array}{l}\text { 4C. Objective list III } \\
\text { (the central OWB focus) }\end{array}$ & $\begin{array}{l}\text { FUNCTIONINGS } \\
\text { (other than satisfaction) }\end{array}$ & $\begin{array}{l}\text { 'UNIVERSAL GOAL' = } \\
\text { avoidance of serious harm to } \\
\text { persons (incl. social } \\
\text { exclusion), }\end{array}$ \\
\hline $\begin{array}{l}\text { 5. Capability / positive } \\
\text { freedom }\end{array}$ & $\begin{array}{l}\text { CAPABILITY } \\
\text { (the range of lives which a } \\
\text { person could attain) }\end{array}$ & \\
\hline 4B. Objective list II & $\begin{array}{l}\text { CAPABILITIES (people's } \\
\text { skills, capacities); and other } \\
\text { characteristics of people }\end{array}$ & $\begin{array}{l}\text { 'BASIC NEEDS' = an } \\
\text { 'optimum' of physical health } \\
\text { and autonomy of agency }\end{array}$ \\
\hline 4A. Objective list I & $\begin{array}{l}\text { CHARACTERISTICS OF } \\
\text { GOODS, which are acquired } \\
\text { through consumption. }\end{array}$ & $\begin{array}{l}\text { 'UNIVERSAL SATISFIER } \\
\text { CHARACTERISTICS' = } \\
\text { adequate nourishment, } \\
\text { shelter, education, } \\
\text { environment, security, } \\
\text { personal relationships, etc. }\end{array}$ \\
\hline 3. Activity & $\begin{array}{l}\text { CONSUMPTION proper } \\
\text { - viz., actual use of }\end{array}$ & \\
\hline
\end{tabular}




\begin{tabular}{|l|l|l|}
\hline & purchases / acquisitions. & \\
\hline 1B. Opulence II & $\begin{array}{l}\text { PURCHASES and other } \\
\text { acquisitions }\end{array}$ & SPECIFIC SATISFIERS \\
\hline $\begin{array}{l}\text { 2. Ch. Preference fulfilment I } \\
\text { 'Utility' as CHOICE, which is } \\
\text { typically assumed to reflect } \\
\text { preference, and (as default } \\
\text { case) weighted according to } \\
\text { purchasing power. }\end{array}$ & \\
\hline 1A. Opulence I & $\begin{array}{l}\text { INCOME AND RESOURCES } \\
\text { / POWER TO ACQUIRE }\end{array}$ & $\begin{array}{l}\text { SOCIETAL } \\
\text { PRECONDITIONS } \\
\text { (MOODS/COMMODITIES }\end{array}$ \\
& PROCEDUR AND \\
& & SATISFACTION \\
\hline
\end{tabular}

The role of the table is not to insist that this is exactly how wellbeing must be conceived. Many of the main determinants of wellbeing, such as family life and friendship, religion and other belief systems, culture and role designations, do not readily fit into this economics-derived perspective. However the extended sequence indicates how several different conceptions of the content (rather than sources) of wellbeing can be seen as focusing on different levels in this sequence. It helps us to grasp the plurality of wellbeing conceptions.

Table 2.4's first column presents the following seven wellbeing concepts, some of which have variants.

1. To judge wellbeing in practice, economists have traditionally focused on level $1 \mathrm{~A}$ : control over or power to acquire commodities, as indicated by income and wealth; and level 1B, the acquisition of commodities. In Sen's terms this focus on control over things is a focus on opulence.

2. Economists have also used the concept of revealed preference: the presumption that choices fully reflect preferences. There are two associated conceptions of wellbeing that focus neither on things nor on further outcomes. First, since the presumption that choices fully reflect preferences is empirically mistaken, the implied or sometimes explicit stance is that wellbeing lies in making choices, whether or not these prove to fulfil ex ante preferences or promote other results. Second is the 
stance that wellbeing consists in the fulfilment of (ex ante) preferences, regardless of the real outcomes they bring. Since preferences can be formulated and focused upon for outcomes at various levels/stages - commodities, characteristics, functionings and so on - the conception of WB as preference fulfilment in fact emerges at several levels. Two are indicated in table 2.4: $6 \mathrm{~A}$ - fulfilment of preferences for obtaining certain goods, and $6 \mathrm{~B}$ - fulfilment of preferences for attaining certain functionings.

3. Somewhat outside economists' categories is a third broad conception of wellbeing as activity per se. It perhaps spans aspects of choice, purchase and consumption, and also includes some functionings and the stages of activity that precede and lead up to income and resources. In face of the accumulated evidence of a "hedonic treadmill' in materially affluent countries, where ever more activity leads to no or very few hedonic gains (and perhaps far smaller gains than if they were not pursued via the path of commodity -production, -acquisition, -bonding and -discarding), this activist conception of wellbeing represents a Promethean defiance. Henry Bruton's On The Search for Well-Being (1997) gives one statement of such a stance, by a distinguished development economist of the 1960s through 1990s.

4. Several stages in the narrative correspond to some 'objective-list' conception of wellbeing, or to some sort of component in an 'objective list': certain characteristics acquired through consumption (this is the level of 'universal satisfier characteristics' stressed by Doyal \& Gough); certain capabilities, seen as skills and abilities; certain functionings, such as long and healthy life; and value fulfilment, eudaimonia. I have grouped them here as variant conceptions of OWB, but one could also treat some or all of them separately.

5. Treated separately in the classification is Sen's category of capability. It too could be treated as an objective-list conception, but it has achieved independent prominence. Arguably the degree of prominence is more than it deserves, for a plausible conception of wellbeing will span a number of aspects, as Sen periodically points out.

6. Preference fulfilment is purportedly central in economists' treatment of wellbeing. Economists, unlike psychologists, retreated from direct attention to utility (ophelimity) as felt wellbeing. ${ }^{v}$ It thereby came to focus instead, in principle, on preference 
fulfilment. In practice, however, this was reduced to wellbeing as choice or as sheer activity (conceptions 2 and 3 above).

7. Lastly, our old friend, wellbeing as pleasure or satisfaction - SWB, or at least one version of it - has been rarely studied by economists, until very recently. It has been left to other disciplines, whose findings most of economics then ignores.

The final column of Table 2.4 presents key components of Doyal and Gough's theory of need, in the same levels/stages format that has been applied to the concepts of wellbeing. Doyal \& Gough's book did not itself make this precise comparison or exact links to the capability approach or wellbeing discourse. In the more limited variant of their theory, the 'universal goal' is 'Avoidance of serious harm: minimally disabled social participation' (1991: 170). This corresponds to the level or narrative-stage of 'functionings' in Sen's sense, what people are and do. The implied basic needs of physical health and autonomy of agency correspond to a level of concrete capabilities, not to Sen's abstracted general notion of capability. Mental health needs enter as requirements of autonomy of agency. ${ }^{\text {vi }}$

\section{Interrelations between concepts of need and concepts of wellbeing}

To probe further the relations between the conceptual fields of needs and wellbeing, Figure 2.1 reformats Table 2.1's modal analysis of types of need, as a Venn diagram. The intersections of the three need modes give five cases, five areas in the diagram.

- The uppermost rectangle represents needs which are wants and/or behavioural drives (in other words, needs in mode A). It consists of areas $1+2+3$.

- The middle rectangle represents needs which are requirements for a given objective (in other words, in mode B). It consists of areas $2+3+4+5$.

- The third rectangle is a subset of the middle one and represents needs as normative priority requirements (in other words, in mode C). It consists of areas $3+4$. This normative concept of need links - somewhat ironically in terms of labelling, as we noted - to the concept of objective wellbeing. 
Figure 2.1. Venn diagram of the three modal usages of 'needs'

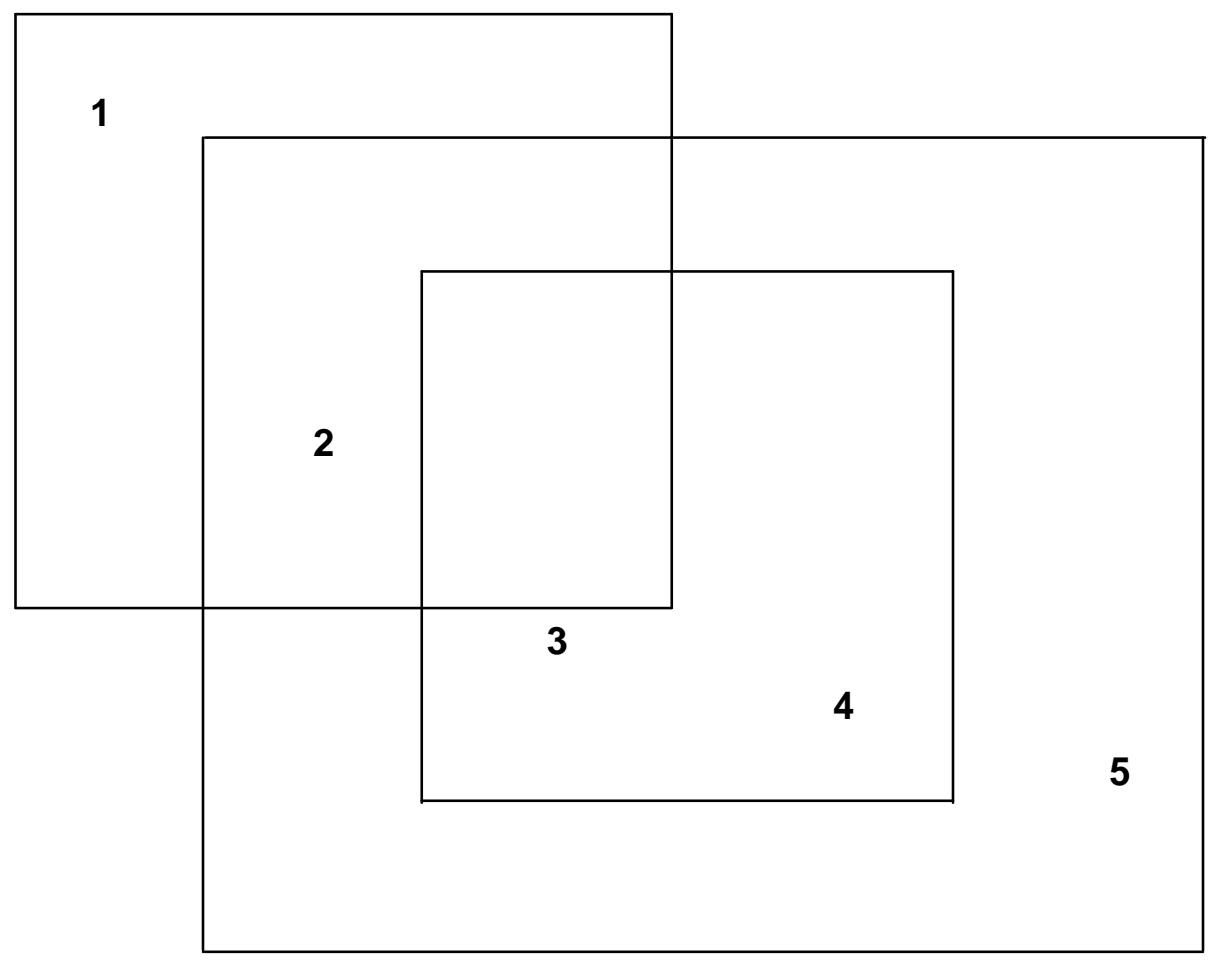

Area/case 3 indicates behavioural drives or wants which fulfil normative priority requirements. In a humanist/welfarist conception the central priority may be human wellbeing, typically interpreted as OWB (the formulation of which may or may not subsume SWB). Behind much of the sloppy usage of the term 'need' lies a presumption that all drives are of the area 3 type. This rests on an exceptionally rosy theory of human nature: that evolution or Providence have selected for us only those drives which lead to the promotion of normative priorities; thus all drives are supposed to be found in area 3 , and areas 1 and 2 are presumed empty. Also contributing to casual usage is a sister presumption, that we have no normative priorities which are not targeted by behavioural drives; in other words, that area 4 is empty.

In reality:

- Some drives fulfil no objective (see area 1 in Figure 2.1); they are non-functional, perhaps outmoded relics from prehistory. ${ }^{\mathrm{vii}}$ 
- Some drives fulfil an objective but not one that is a normative priority (case 2). This could be the case for some drives that promote SWB that is not considered OWB; possibly the drives of the addict. Some drives are even dysfunctional, leading to undesirable outcomes. They might be evolutionary experiments that failed but have not been eliminated, perhaps because too deeply wired-in, or, again, that may once have been functional but became outmoded.

- Many requisites for particular objectives are not drive-based (cases 4 and 5). Uunfortunately, some of these concern normative priority objectives (case 4). Some case 4 instances may be examples that promote OWB but not SWB.

- Case 5 concerns instances where a requisite serves some function but one that is not of normative priority and that, perhaps fortunately, has no behavioural drive behind it.

In sum, case 3 is the ideal or classical case, but is not the only one, contrary to those who treat the term 'need' in a way that does not distinguish modes. A more realistic assessment is that many drives do not do promote normative priorities, some of these drives being dangerous and some indifferent; and that many functional requirements and normative priorities are not drive-based.

The danger case is case 2, where drives fulfil non-priority objectives, perhaps even antiobjectives. The other problem case is case 4 , where normative priority objectives lack a behavioural motor behind them; a need's sheer lack does not itself 'serve to motivate or mobilise the subject' (Jackson et al. 2004: 11). Case 1 might be problematic too: drives that fulfil no objective instead divert us. Case 5 concerns undriven objectives of no significance and appears innocuous.

We have a number of interesting conclusions from this further step in modal analysis. Case 3 is not the only important case; and the value of needs discourse is not limited to or by the occurrence of case 3. Cases 1,2 and 4, none of which matches the classical conception of needs, are all important cases for thinking about the promotion of wellbeing. Fulfilment of mode $A$ needs is not the sole and guaranteed route to wellbeing. 


\section{METHODOLOGICAL AND PROGRAMMATIC REFLECTIONS}

To draw conclusions on how wellbeing research can benefit from needs theory, let us review what needs theory is for, then ask in what ways it might serve wellbeing research, and wellbeing research in low-income countries in particular.

\section{Needs theory for wellbeing research?}

What is the goal of needs theory? First, it has an explanatory branch and purpose: to extend our explanatory repertoire beyond 'economic man' and other overly crude models. Second, it has a normative task: to structure, rationalise and humanise policy prioritisation, to extend our evaluative repertoire beyond the criterion of per capita income, and also beyond what is usually now embodied in Poverty Reduction Strategy Papers (PRSPs). Thirdly, in both cases it has a communicative function: to further the explanatory and normative tasks by frameworks that are simple enough, yet robust enough, to be both usable and not too misleading in routine professional and political discourse.

The post-fall revival in the 1990s of needs theory in both explanatory and normative branches, sometimes under new names and in more advanced versions, suggests that it can contribute helpfully in these roles. We see important explanatory work, such as that of Ryan and Deci, and normative and policy work on the HDI, Human Development Reports, Millennium Development Goals, humanitarian intervention and - insofar as human rights must often rest on claims about human needs (Doyal \& Gough 1991; Galtung 1994; Gasper 2005c) - on rights-based approaches.

Specifically for wellbeing research, our Venn diagram analysis shows that needs discourse offers one valuable framework in the study of wellbeing, provided it is treated as a complex frame that gives space for our minds to work - as a tool in a research programme. It generates an agenda of three important types of situation for us to study (cases 1, 2 and 4), in addition to the optimistic case 3 that is widely presumed.

How far is Doyal and Gough's theory, a normative theory constructed for ethics and planning with primary reference to high-income countries, relevant for the study of wellbeing in low-income countries? Needs discourse has a role in critiquing income measures as extremely insufficient and quite often misleading. Most evidence suggests 
that income remains one significant contributor to subjective wellbeing for low-income countries but not beyond middle-income levels. ${ }^{\text {viii }}$ Doyal and Gough's approach, the spirit of which we presented in Section 3, contributes an intellectual clarity and a refined framework for instrumental and normative analyses. It helps us think about modes, levels, indicators, the choices of normative priority criterion, and the use of available theory and evidence from many fields, together with practical reason, to specify the factors that influence key elements in real people's lives. At the same time, it is not itself a complex explanatory framework, and should be complemented by good explanatory analyses, including from within needs mode A. Arguably, the revival of needs approaches may only be sustained if backed and guided by such deeper explanatory research. Effective conceptualisations, albeit working simplifications, might be those that are informed by sustained investigation of the empirics. Let us look at two areas.

\section{Research on the dynamics of need definition}

Hamilton (2003) laments the divorce between, in our terms, mode A analyses of needs and mode $\mathrm{C}$ analysis of need, and the neglect, in his view, of the former. While showing limited insight into work in modes $B$ and $C$, and exaggerating the difference between his conceptual framework and that of Doyal \& Gough, his book on needs interestingly tackles interactions between the modes, notably the dynamics of transformation of mode A needs, and the processes of emergence of some felt needs as approved priorities. Hamilton notes that drives are not only instinctual in origin but are continually newly generated and also dissipated. He investigates the dynamics of transformation, including from pure wants to felt needs in the sense of drives, and how this mode-A need generation and transformation can affect what are instrumental requirements and agreed priorities. There can be moves from the status of pure want to the status of felt mode-C need, i.e. felt approved needs. Sometimes the reverse happens.

Figure 2.1 also arouses our curiosity concerning its area 4: normative needs which are not felt needs. In needs-mode A, needs which are not felt means unconscious drives; in mode $B$ unfelt needs concern, for example, requirements for professional success which are not part of a person's desires-system and are sometimes even inconsistent with it; whereas in mode $\mathrm{C}$ they concern any requirements for approved goals (e.g. health) which are not part of the desire-system. To be part of a person's system of wants and desires is of course not sufficient for ensuring need fulfilment; in commodity-based 
societies, for example, law-abiding members who have no money are unable to fulfil many or most of their wants or needs. But for normative needs to be not part of the wants-system raises particular problems, which a wellbeing oriented needs approach will investigate. Can space 4, the sphere of priority needs that are divorced from wants, be diminished? - by developing wants corresponding to those needs, or finding functional substitutes for fulfilment of those needs?

\section{Research on substantive interconnections between wellbeing and need fulfilment}

In mode A discourse, 'real needs' are drivers of behaviour; in mode C discourse, 'real needs' are those 'needs' whose fulfilment brings wellbeing. Not all (mode A) need fulfilment leads to wellbeing, whatever our interpretation of the latter - except perhaps in the bizarre yet influential interpretation of wellbeing as sheer activity. Using Manfred Max-Neef's language, we can speak of 'pseudo-needs': behavioural drives which fail to bring mature reflective satisfaction. Max-Neef's (1991) typology of needs and satisfiers is thought-provoking and should also be research-provoking. 'Pseudo satisfiers' give only fleeting fulfilment; 'violators' completely fail to satisfy, yet one may be habituated to them; 'inhibiting satisfiers' satisfy one need (often a short-term one) but at the cost of reducing satisfaction of other needs; and 'synergistic satisfiers' fulfil several needs at once, unlike 'singular satisfiers'. We do typically seek to fulfil several needs at once, as cultural theorists demonstrate - but how well the satisfiers that we choose do this requires empirical evaluation and the answer is frequently critical. Modern market society can drive us onto commercialised hedonic treadmills which bring no enduring values but which destroy some values and destroy our habitat (Jackson et al. 2004).

The Venn diagram thus illustrates the sort of research agendas on wellbeing that arise in mode $\mathrm{C}$ needs discourse. These agendas are partly empirical, drawing from investigations in mode B: what leads to what, under which circumstances?; and partly ethical, in arguments about the normative status of the outcomes and processes, for example in the discussion of different interpretations of 'wellbeing'. The empirical agenda has been insightfully pursued by, for example, Deci and Ryan, Diener, Illich, Robert Lane, Maslow, Theodore Roszak, Tibor Scitovsky and others. The ethical agenda has been pursued by philosophers. The deepest insights may come from authors who connect and cross-fertilise the two agendas, such as Fromm and Galtung, Giri, Nussbaum and Sen. 


\section{Politics of discourse}

The research agendas of needs and wellbeing are of fundamental importance. How can these linked research programmes proceed effectively in political-intellectualorganisational space, aware not only of the precision, logic and empirical reference of discourse but also of its politics?

One lesson from the rise and fall of the basic needs approach in the 1960s to 1980s is the importance of clarification of concepts. We must in addition keep on monitoring them. Language in such territories is slippery and not stable, even if it appears stabilised in the short run. The word 'want', for example, evolved from meaning lack or need, to now mean desire.

A second possible lesson is of the importance of labels. 'Basic needs' as a label was unappealing to many. 'Wellbeing' appears to work better. But how appealing, we should consider and check, is 'wellbeing' as a label really? When will it promote priority to the basic needs of the poorest and under what conditions?

A third lesson is that is essential to invest not only in cross-disciplinary alliances but to build trans-disciplinary cooperation. The basic human needs work remained, despite the valiant efforts of thinkers such as Galtung, a weakly integrated product of a series of weakly cooperating intellectual communities, from economics, philosophy, psychology, health and nutrition. Many of the economists involved felt apparently that they could do nearly the whole job, or at least the job of synthesis; but they failed to build a structure with the depth and sophistication required to withstand the scepticism and even hostility of diverse stakeholders and other intellectual and political traditions. Presently too, the wellbeing and human development streams of work remain insufficiently connected. The UNDP-related Human Development work continues dominated by (broad-minded) economists, who are only recently and tentatively opening to the riches of research on wellbeing and needs. Fortunately, a strong feature of the WeD work is close long-term cooperation between researchers from psychology, health, economics, anthropology and social policy. Outreach to others, in philosophy, politics, sociology, planning, education and social work, and in the humanities, will be important too. 


\section{REFERENCES}

Bruton, Henry, 1997. On the Search for Well-Being. Ann Arbor: University of Michigan Press

Darcy, James \& Charles-Antoine Hofmann, 2003. According to Need? Needs assessment and decision-making in the humanitarian sector. Humanitarian Policy Group Report 15. London: Overseas Development Institute.

Dasgupta, Partha, 1993. An Inquiry into Well-Being and Destitution. Oxford: Clarendon Press.

Douglas, Mary, Des Gasper, Steven Ney, Michael Thompson, 1998. Human Needs and Wants. Ch.3, pp.195-263, of Human Choice and Climate Change, Vol. 1: The Societal Framework, edited by Steve Rayner and Elizabeth L. Malone; Colombus, OH: Battelle Press.

Doyal, Len, \& Ian Gough, 1991. A Theory of Human Need. London: Macmillan.

Dutt, Amitava K., 2001. 'Consumption, Happiness and Religion', in Dutt, A. and Jameson, K. P., eds., Crossing the Mainstream. Notre Dame, IN: University of Notre Dame Press, pp. 133-169

Furnham, Adrian, \& Alan Lewis, 1986. The Economic Mind - the Social Psychology of Economic Behaviour. Brighton: Harvester/Wheatsheaf.

Galtung, Johan, 1994. Human Rights in Another Key. Cambridge: Polity Press.

Gasper, Des, 1996. Needs and Basic Needs - a clarification of foundational concepts for development ethics and policy. Pp.71-101 in Questioning Development, ed. G. Koehler, C. Gore et al., Marburg: Metropolis. And as ISS Working Paper 210.

Gasper, Des, 2004a. The Ethics of Development: From economism to human development. Edinburgh: Edinburgh University Press.

Gasper, Des, 2004b. Human Well-Being: Concepts and Conceptualizations. Working Paper 388, Institute of Social Studies, The Hague; iss.www.nl.; and WIDER Working Paper, for project on Measuring Well-Being; Helsinki: WIDER.

Gasper, Des, 2005a. Securing Humanity - Situating 'Human Security' as Concept and Discourse. $J$. of Human Development, 6(2), 221-245.

Gasper, Des, 2005b. Subjective And Objective Well-Being in Relation to Economic Inputs: Puzzles and Responses. Review of Social Economy, LXIII (2), 177-206.

Gasper, Des, 2005c: 'Needs and Human Rights', pp. 269-272 in The Essentials of Human Rights, eds. R. Smith \& C. van den Anker. London: Hodder \& Stoughton.

Gasper, Des, and Irene van Staveren, 2003. Development as Freedom - and as What Else? Feminist Economics, 9 (2/3), 137-161.

Hamilton, Lawrence, 2003. The Political Philosophy of Needs. Cambridge: Cambridge U.P. 
Illich, Ivan, 1978. Towards a History of Needs. New York: Pantheon.

Jackson, Tim, Wander Jager, \& Sigrid Stagl, 2004. Beyond Insatiability - Needs theory, consumption and sustainability. Working Paper 2004/2, ESRC Sustainable Technologies Programme, University of Surrey.

Kuper, Adam, \& Jessica Kuper (eds), 1994. The Social Science Encyclopedia, $2^{\text {nd }}$ edition. London: Routledge.

Lea, Stephen, Roger Tarpy and Paul Webley, 1987. The Individual in the Economy. Cambridge: Cambridge U.P.

Penz, Peter, 1986. Consumer Sovereignty and Human Interests. Cambridge: Cambridge U.P.

Penz, Peter, 1991. The Priority of Basic Needs. Pp. 35-73 in K. Aman ed., Ethical Principles for Development: Needs, Capacities or Rights, Upper Montclair, NJ: Montclair State University.

Rayner. Steve, \& Elizabeth Malone, eds., 1998. Human Choice and Climate Change (4 volumes). Colombus, OH: Battelle Press.

Ryan, Richard M., \& Edward L. Deci, 2001. On Happiness and Human Potentials: A Review of Research on Hedonic and Eudaimonic Well-Being. Annu. Rev. Psychol., 52, 141-66.

St. Clair, Asuncion Lera, 2004. 'The role of ideas in the United Nations Development Programme', in Bøås, M. and McNeill, D., eds., Global institutions and development: framing the world? London: Routledge,

St.Clair, A. L. 2005.. 'Global Poverty: The co-production of knowledge and politics', Global Social Policy,

Taylor, Paul, 1959. 'Need' Statements. Analysis, 19(5), 106-111.

Thomson, Garrett, 1987. Needs. London: Routledge.

Witkin, B.R. \& J.W. Altschuld 1995. Planning and Conducting Needs Assessments. Sage. 
'I would like to thank lan Gough for very helpful advice.

ii The study later implicitly adds perhaps other meanings of need: 4 . what is required for reducing the non-fulfilment of basic human needs, and 5. what is required for providing relief assistance or whatever other policy response. Each of these requisites will then have its own requirements.

iii Within these modes, there are dozens of different specific concepts of need (as indicated in Gasper 1996, 2004a). Some are worth grouping further and keeping separate from others. For example, in mode $A$, needs which are expected to explain wants might be contrasted with needs that are expected to explain satisfactions; likewise, inborn needs against inculcated needs.

iv From decades of research, Veenhoven (2004) advises that we should use a $3 \times 3$ rather than $2 \times 2$ matrix of categories, with nine possibilities rather than four, while recognizing that we face a spectrum of possibilities along each axis rather than clear cut divides.

${ }^{\vee}$ Let alone attention to utility as the possession of useful characteristics or performance of useful functionings, as considered by many sociologists, psychologists, designers, engineers and planners.

vi Doyal and Gough discussed 'capabilities/functionings' as a package notion (1991: 156) and thus did not make the precise links. They instead tried to link their 'basic needs' to the level of functionings (1991: 156). Nor did they use the distinction between capability (Sen's category) and capabilities (Nussbaum's).

vii In the case of wellbeing interpreted as activity, however, this category might be null, since all activity is deemed good.

viii Income remains a significant contributor until upper middle-income status (perhaps around $\$ 8,000$ per capita p.a., suggested the World Values Survey (Dutt 2001). 